\title{
THE RELATIONSHIP OF POLYSACCHARIDES TO SOIL AGGREGATION
}

\author{
C. J. Acton', D. A. Rennie and E. A. Paul ${ }^{3}$ \\ [Received for publication May 31, 1962]
}

\begin{abstract}
Studies were conducted on two soil types to determine whether variations in level of aggregation, induced by adding wheat straw, were accompanied by significant changes in the polysaccharide content of the soils.

The addition of finely ground wheat straw to the soils, followed by varying periods of incubation, markedly improved the level of aggregation in both soils. Where nitrogen was added together with the straw, the percentage of aggregates $>0.5$ and $0.1 \mathrm{~mm}$. diameter was reduced significantly as compared to the straw treatment alone. The data indicate that maximal structural improvement due to straw additions can only be attained where $\mathrm{N}$ is maintained at a relatively low level.

The level of aggregation of the variously treated soils was shown to be approximately 35 per cent dependent on the 'microbial gum' content of the soil samples. This low level of correlation was due in part to the fact the soil samples. The maximum level of aggregation was attained at a different sampling period than maximum accumulation of 'microbial gum'. Also, appreciable contents of polysaccharides were found in the humin and humic acid as well as the fulvic acid fractions of the soil organic matter. It is concluded that level of aggregation is a function, not only of the 'microbial gum' content of the soil, but also of the carbohydrate carbon content of the humic acid-humin fraction.
\end{abstract}

\section{INTRODUCTION}

The addition of bacterial polysaccharides to soil has been shown by a number of workers $(3,6,9,11)$ to result in an increase of the level of aggregation. Rennie et al. (11) demonstrated a marked aggregating effect when a bacterial polysaccharide was added to a silt loam; the percentage aggregates greater than 0.1 millimeter was increased by approximately 100 per cent. In addition, polysaccharide materials isolated from soil were shown to be effective aggregating materials.

Halstead (7) suggested that, if the soil polysaccharide content is related to aggregation, there should be a correlation of the percentage extractable gum with the per cent aggregation; no correlation was obtained between extractable gum from the fulvic acid fraction of the soil and percentage aggregates $>0.1$ millimeter in diameter on a Spencer silt loam soil under different crops and lime levels. Mehta et al. (10) similarly failed to confirm the findings of earlier workers that polysaccharides played a significant role in aggregate formation. However, data reported by Toogood and Lynch (12) indicated a definite relationship between total soil polysaccharide content, measured colorimetrically, and mean weight diameter of aggregates of soil samples taken from selected crop rotational sequences from the Breton plots. Similarly, Chesters et al. (4) concluded, after studying the influence of organic matter, microbial gum, clay, and free iron oxide content of selected aggregate size ranges of four Wisconsin soils, that the microbial gum content was the most important single factor affecting level of aggregation.

The present study was undertaken to evaluate the influence of fertility level ( $\mathrm{N}$ and $\mathrm{P}$ ) on the level of aggregation, and 'microbial gum' and poly-

IContribution from the Department of Soil Science, University of Saskatchewan, Saskatoon, Sask. This paper is based in part on a thesis submitted in partial fulfilment of the requirements of the M.Sc.

This paper is based in part on a thesis
degree, University of Saskatchewan.

2R Uskatoon Research Station, Canada Department of Agriculture.

Associate Professor and Assistant Professor, University of Saskatchewan. 
saccharide content of straw amended soils. More specific relationships were studied in that the level of aggregation of the soils was related to the content of carbohydrates present in the various fractions of the soil organic matter.

Soil

\section{MATERIALS AND METHODS}

The soil samples used in these investigations were obtained from the Aa horizon of a Dark Brown Solodized Solonetz (Trossachs) and an Ae horizon of a Low Humic Eluviated Gleysol (Oxbow) profile. Significant data characterizing the soils are given in Table 1 .

Measurement of Soil Aggregation

The procedure used for the measurement of soil aggregation is essentially the method outlined by Rennie (11). Aggregate analysis was conducted on both air-dry and spray-wetted samples. The percentage of water stable aggregates $>0.01$ and $>0.5$ millimeter in diameter were used as an index of soil aggregation.

Measurement of Microbial Gum and Polysaccbarides

Rennie's modification (11) of the procedure of Forsyth (5) was used to determine the microbial gum content. The polysaccharide content of the soils was measured as described in the preceding paper (1).

\begin{tabular}{|c|c|c|c|c|c|c|c|}
\hline $\begin{array}{l}\text { Soil } \\
\text { assoc. }\end{array}$ & $\mathrm{pH}$ & O.M. & $\begin{array}{c}\text { Coarse } \\
\text { sand } \\
1-0.5 \mathrm{~mm} .\end{array}$ & $\begin{array}{c}\text { Medium } \\
\text { fine sand } \\
0.5-0.1 \mathrm{~mm} .\end{array}$ & $\begin{array}{c}\text { sand } \\
>0.05 \mathrm{~mm} .\end{array}$ & Silt & Clay \\
\hline Trossachs & 6.0 & 4.4 & 10.0 & 12.7 & 53.2 & 26.0 & 20.8 \\
\hline Oxbow & 6.2 & 2.5 & 15.6 & 10.7 & 39.2 & 49.8 & 11.0 \\
\hline
\end{tabular}

$*_{\mathrm{O} . \mathrm{M} .}=\% \mathrm{C} \times 1.724$

Table 2. - The influence of STRaw, with and without nitrogen and PHosphorus, ON THE LEVEL OF AGGREGATION OF TROSSACHS SOIL

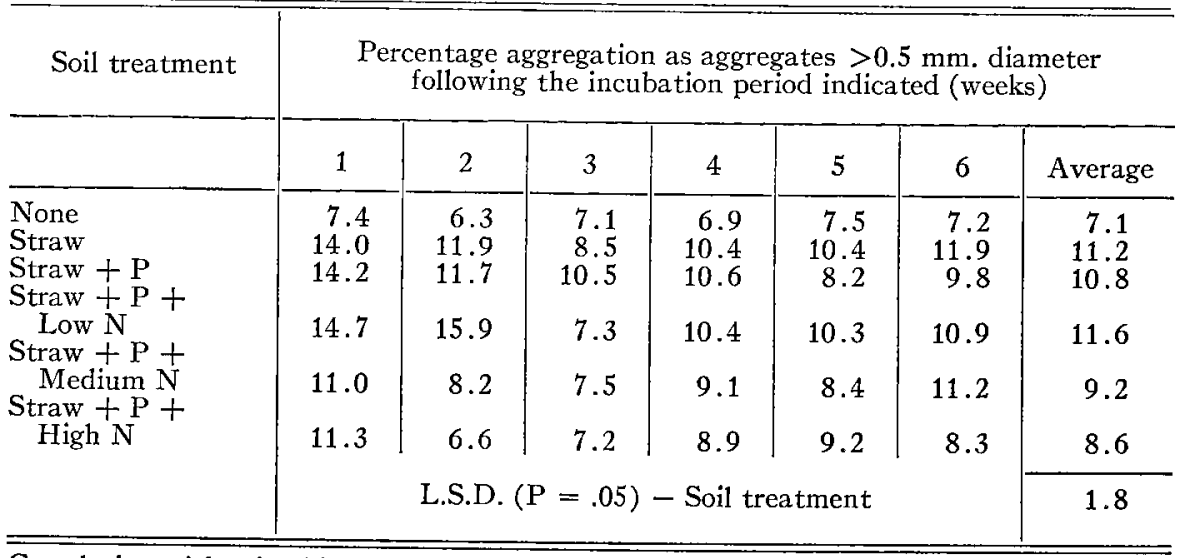

Correlation with microbial gum, $r=0.616^{* *}$

**Significant at the 0.01 probability level 


\section{RESULTS}

In an experiment designed to study the effect of the fertility level of straw-amended soils on the aggregation of the soil, finely ground wheat straw and solutions of $\mathrm{KH}_{2} \mathrm{PO}_{4}$ and $\mathrm{NH}_{4} \mathrm{NO}_{3}$ were added to the Trossachs and Oxbow soil samples. Wheat straw was incorporated with the soil at a rate equivalent to 20 tons per acre, $\mathrm{KH}_{2} \mathrm{PO}_{4}$ at a rate equivalent to 200 pounds $\mathrm{P}_{2} \mathrm{O}_{5}$ per acre, and $\mathrm{NH}_{4} \mathrm{NO}_{3}$ at rates equivalent to 100,300 , and 600 pounds of nitrogen per acre. The amended and unamended samples were incubated in a constant temperature growth chamber as described in the preceding paper (1). The percentage of water stable aggregates was determined each week for a period of 6 weeks.

The incorporation of straw into the Trossachs surface soil significantly increased the percentage of both $>0.1$ and $>0.5$ millimeter aggregates (Tables 2 and 3). Phosphorus amendment, together with the straw, did not change the level of aggregation, but nitrogen tended to decrease the level of both 0.5 and 0.1 millimeter diameter aggregates. This decrease was significant at the highest rate of nitrogen used.

The percentage of aggregates $>0.5$ millimeter diameter reached a maximum after 1 week of incubation and then declined. The maximum level of the $>0.1$ millimeter diameter aggregates was not reached until the later sampling periods. It should be noted that the microbial gum content reached a maximum at approximately 1 week after incorporation of the straw and then declined somewhat (1). The lag in maximum level of small aggregate formation in relation to the production of microbial gum in the soil is reflected in the low correlation coefficient, 0.221 , between microbial gum content of the soil and percentage aggregates $>0.1$ millimeter diameter. In contrast, a highly significant correlation coefficient of 0.616 was calculated between the gum content of the soil and the percentage aggregates $>0.5$ millimeter diameter. This would indicate that the microbial gum produced during decomposition of the straw is partially responsible for the increase in aggregates $>0.5$ millimeter diameter.

TABLE 3. - ThE INFLUENCE OF STRAW, WTTH AND Without NITROGEN AND PHOSPHORUS, ON THE LEVEL OF AGGREGATION OF TROSSACHS SOI

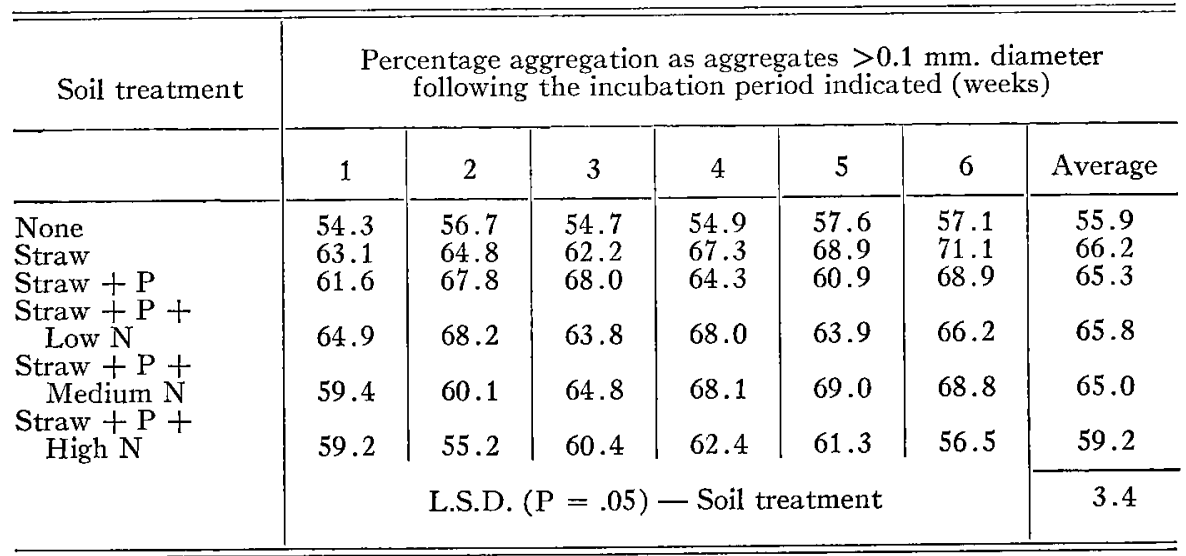

Correlation with microbial gum, $\mathrm{r}=0.221$ 


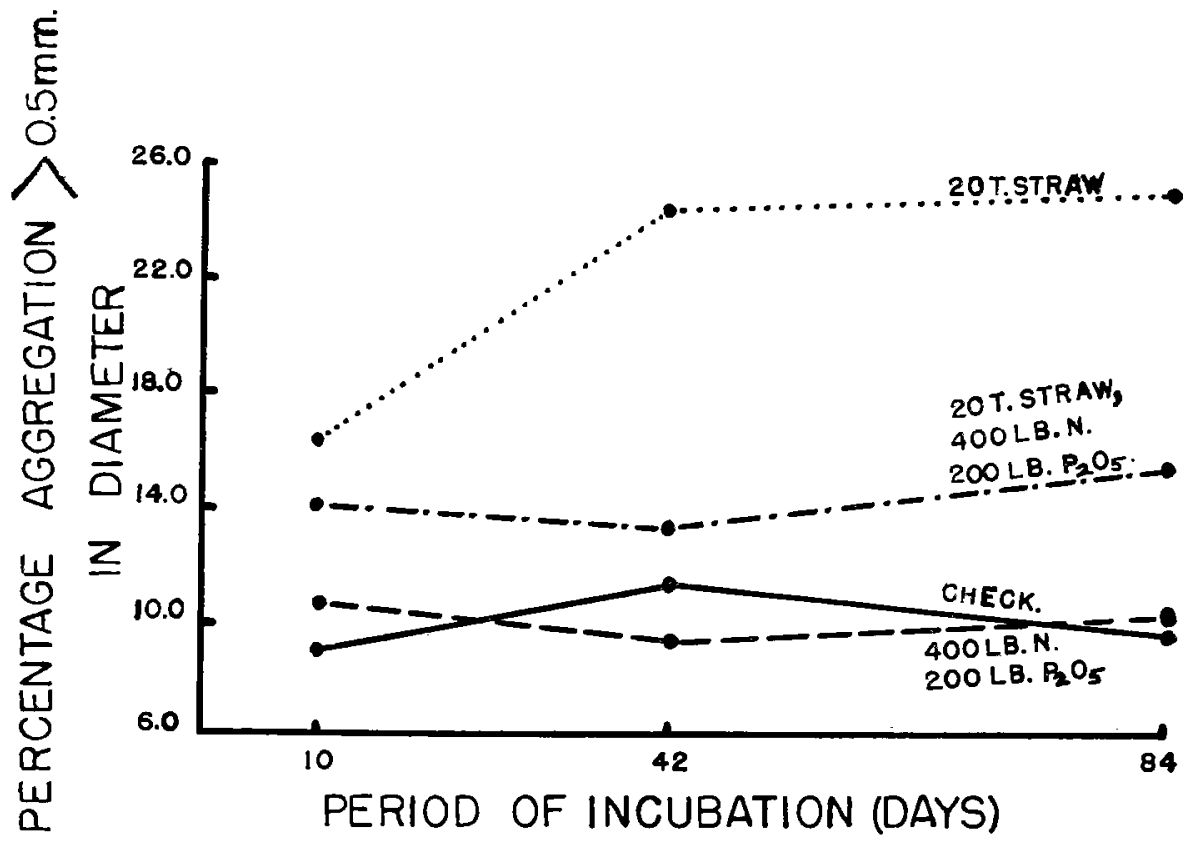

Figure 1. The effect of soil treatment and period of incubation on the per cent aggregates $>0.5$ millimeter in diameter-Trossachs soil.

The aggregation data obtained where the dry soil samples were suddenly immersed into the water (no pre-wetting procedure followed) have not been included since the data were very variable. While the same general conclusions, as outlined above, could have been reached, it was much more difficult to establish any definite trends due to treatments or time. Correlation coefficients calculated between level of aggregation and gum content were very low and not significant. The spray-wetting pre-treatment is to be preferred in experiments where small variations in the level of aggregation are expected.

Spray-wetting increased the measurable per cent aggregation for all size of aggregates; this increase in level of aggregation due to slow pre-wetting prior to wet-sieving was much more marked for the larger aggregates. This increase in measured level of aggregation has been explained by Rennie (11) as being due to the shattering of aggregates by entrapped air when they are suddenly wetted. Spray-wetting the samples prior to wet sieving enables the air in the soil pores to be gradually replaced by water, in this way preventing undue disruption of the aggregates by the entrapped air.

Since the data obtained from the Oxbow soil samples followed similar trends to those discussed above for the Trossachs soil, these have been omitted from this paper.

Approximately 20 per cent of the microbial gum precipitate has been shown to be comprised of polysaccharide material (1). The relatively low correlation between microbial gum present and percentage aggregation could well be due to the impurities present in the precipitated gum fraction. 


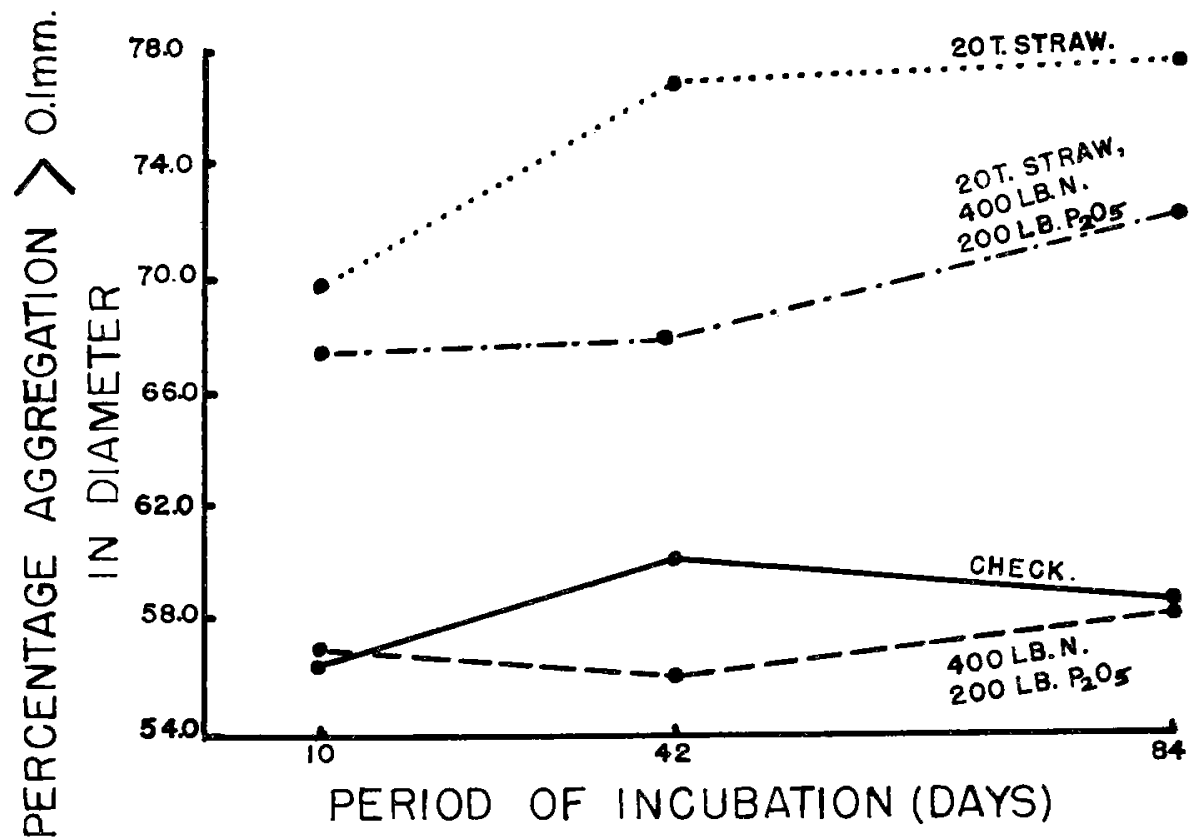

Figure 2. The effect of soil treatment and period of incubation on the per cent aggregates $>0.5$ millimeter in diameter--Trossachs soil.

Also, it is possible that other carbohydrate carbon present in the organic matter fraction may be of importance in aggregate formation. In the further experiment described below the polysaccharide content of the soil was determined using the colorimetric anthrone procedure outlined by Brink et al. (2).

A second incubation experiment was set up using the two soils described previously. Ammonium nitrate and potassium di-hydrogen phosphate were added to the straw amended (20 tons per acre) and unamended soils at a rate of 400 pounds $\mathrm{N}$ and 200 pounds $\mathrm{P}_{2} \mathrm{O}_{5}$ per acre. Sufficient replicates were prepared to permit sampling at 10,42 and 84 days. The polysaccharide contents of the incubated soil samples were determined on the complete soil and on various fractions of the organic matter.

The influence of the wheat straw amendments, with and without nitrogen and phosphorus fertilization for the three sampling periods is illustrated in Figures 1 and 2 for the percentage aggregation $>0.5$ and 0.1 millimeter diameter respectively. Similar conclusions can be drawn using either aggregate size as an index of the effect of various amendments on soil structure. The addition of straw alone resulted in a maximum level of aggregation at all sampling times. The addition of nitrogen and phosphorus to the straw treated samples resulted in a decrease in aggregation as compared to the straw treatment alone. This decrease in aggregation was highly significant after the 42- and 84-day sampling period. The addition of nitrogen or phosphorus to the soil alone did not change the level of aggregation significantly. 


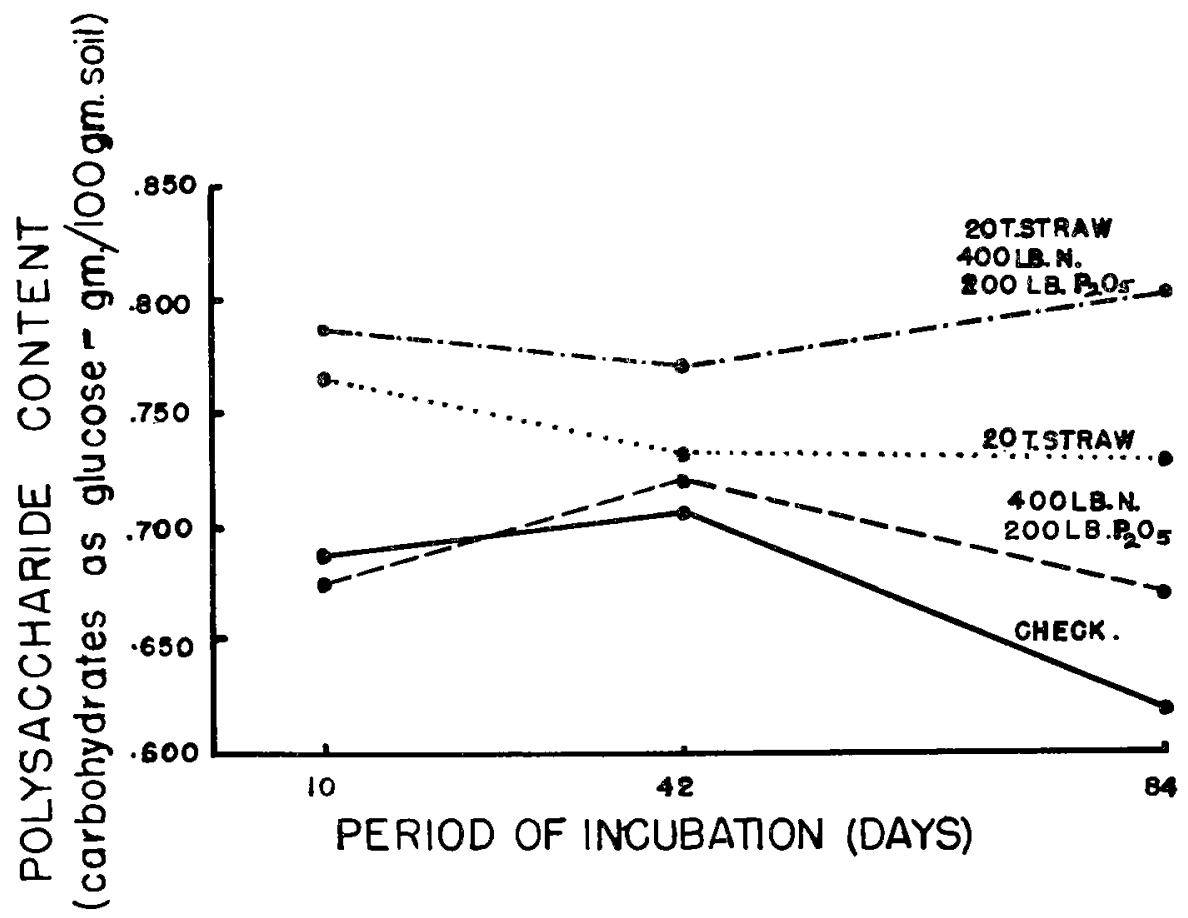

Figure 3. The effect of soil treatment and period of incubation in the total polyaggregates $>0.1$ millimeter in diameter-Trossachs soil.

The polysaccharide content of the samples incubated for 10,42 , and 84 days reached a maximum at the first sampling period and did not change significantly during the remainder of the experiment (Figure 3). There appears to be a slight decrease in the polysaccharide content for the straw alone - treatment after 42 or 84 days respectively as compared to the 10-day sampling period. It is also evident that the straw plus nitrogen and phosphorus treatment resulted in maximum polysaccharide formation as compared to the straw alone treatment. It is interesting to note that these data do not conform to the aggregation data. Maximum polysaccharide formation was recorded after 10 days' incubation, while maximum aggregate formation was not realized until after 42 days' incubation. In addition, the soil receiving straw alone was much better aggregated than the soil receiving straw plus nitrogen and phosphorus. Maximum polysaccharide formation was recorded in the latter treatment.

Again, the data obtained on the Oxbow soil samples showed similar trends to those noted above for the Trossachs soil. Consequently, for sake of brevity, these were not included in this paper.

Since the anthrone determined polysaccharide content of the complete soil resulted in distinctly different trends with time than that obtained with aggregate analysis, it might be concluded that the polysaccharide content of the soil is not directly related to the level of aggregation. To determine the significance of these rather conflicting data, a fractionation of the organic 


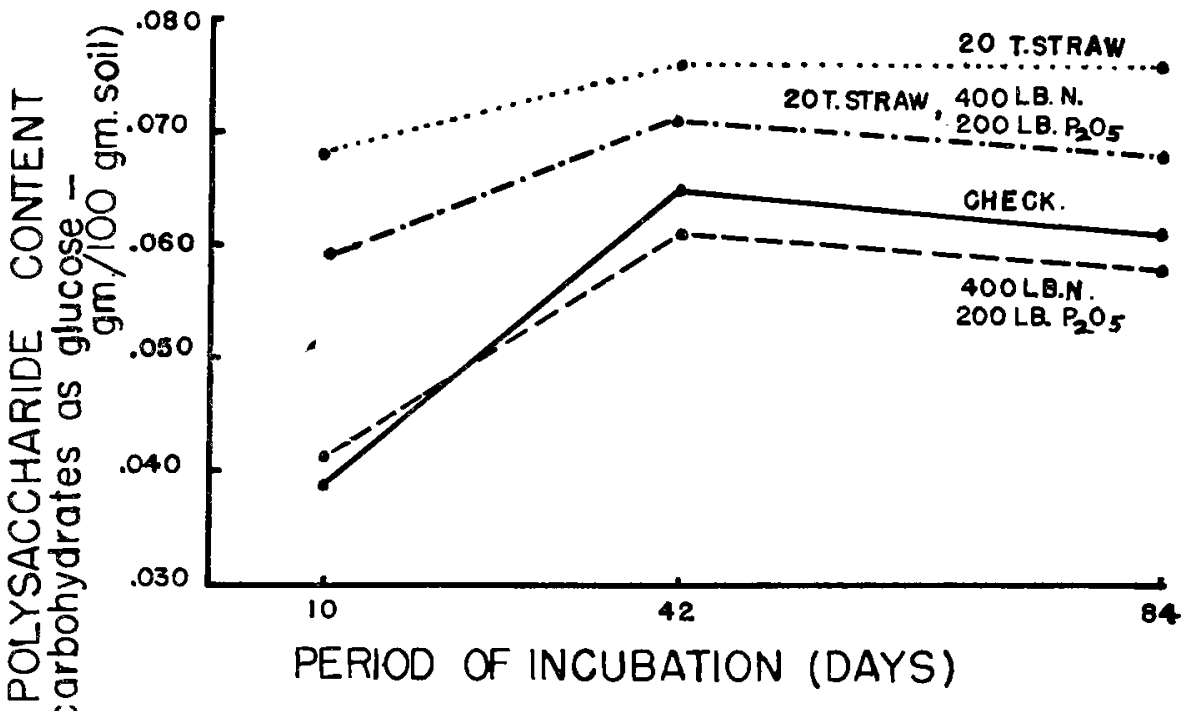

FigURe 4. The effect of soil treatment and period of incubation on the polysaccharide (carbohydrate carbon) content of the precipitated gum fraction of the Tirossachs soil.

fraction of the soil was carried out and the anthrone determined polysaccharide content of the various fractions was measured. It may be of significance that the polysaccharide content of the precipitated gum fraction of the fulvic acid (Figure 4) fraction followed the trend in aggregation much more specifically than did the polysaccharide contents of the complete soil. This relationship was confirmed by calculation of correlation coefficients between the percentage aggregation and the polysaccharide content of the complete soil, and the various fractions of the organic matter (Table 4). The polysaccharide content of the precipitated gum fraction correlated significantly with the percentage of water stable aggregates greater than 0.5 millimeter in diameter as well as the aggregates greater than 0.1 millimeter in diameter. In addition, the highly significant correlation between the polysaccharide content of the complete soil and that of the fulvic acid fraction with the percentage of water stable aggregates greater than 0.1 millimeter in diameter indicates a close relationship between the polysaccharide content of these systems and the level of aggregation of the soil. The poor correlation with the aggregates greater than 0.5 millimeter in diameter possibly indicates that the polysaccharides measured in the complete soil and other fractions of organic matter are contributing mainly to the formation of the smaller sized aggregates.

The correlation coefficients calculated between level of aggregation, and the polysaccharide content of the complete soil, and various organic matter fractions for the low organic matter gleysolic Oxbow soil are given in Table 5. The sample was characterized by a very platy structure, and initially contained approximately one-third as much polysaccharide material as the Trossachs soil. The high correlations between 
both size of aggregates and the polysaccharide content in the complete soil and various fractions of the organic matter undoubtedly reflect the marked changes in structure and polysaccharide content brought about by the various straw and fertilizer treatments. It can be concluded that the polysaccharide content in all the fractions separated is likely responsible for or closely associated with the aggregation phenomena.

\section{DISCUSSION AND CONCLUSIONS}

The addition of finely ground wheat straw to Trossachs and Oxbow soil samples, followed by incubation, increased both the level of aggregation and microbial gum (and polysaccharide) content of the soils. High fertility (addition of $\mathrm{N}$ and $\mathrm{P}$ ) reduced the percentage of aggregates $>0.5$ and $>0.1$ millimeter diameter, and the gum and polysaccharide content. The addition of nitrogen and phosphorus to the straw amended soils undoubtedly increased the rate of decomposition of the straw (8); the 'gum' content of the soils, an oxidative assimilation product of diverse soil micro-organisms, decreased accordingly. It can be concluded that the addition of straw to soils will result in maximum structural improvement only where $\mathrm{N}$ and $\mathrm{P}$ are maintained at relatively low levels.

The microbial gum or polysaccharide precipitated from the fulvic acid fraction of the soil organic matter of the amended and non-amended Trossachs and Oxbow soil samples correlated significantly but not highly (approximately 35 per cent dependent) with the level of aggregation. This

Table 4. - Correlation COefFicients of the POlysaccharide CONTENT OF Various FRACTIONS OF THE SOIL WITH PERCENTAGE AGGREGATION OF TROSSACHS SOIL

\begin{tabular}{l|c|c|c|c|c}
\hline \hline & $\begin{array}{c}\text { Complete } \\
\text { soil }\end{array}$ & $\begin{array}{c}\text { Humic acids } \\
+ \text { humin }\end{array}$ & $\begin{array}{c}\text { Fulvic } \\
\text { acids }\end{array}$ & $\begin{array}{c}\text { Acetone } \\
\text { soluble }\end{array}$ & $\begin{array}{c}\text { Precip- } \\
\text { itated } \\
\text { gum }\end{array}$ \\
\hline $\begin{array}{c}\text { Per cent aggregation } \\
>0.5 \text { mm. diameter } \\
\begin{array}{c}\text { Per cent aggregation } \\
>0.1 \text { mm. diameter }\end{array}\end{array}$ & 0.423 & 0.516 & 0.565 & 0.488 & $0.629^{*}$ \\
\hline \hline
\end{tabular}

**Significant at 0.01 probability level

*Significant at 0.05 probability level

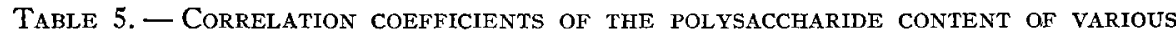
FRACTIONS OF THE SOIL WITH PERCENTAGE AGGREGATION OF THE AE HORIZON OF A LOW HUMIC ELUVIATED GLEYSOL (OXBOW SOIL)

\begin{tabular}{l|c|c|c|c|c}
\hline \hline & $\begin{array}{c}\text { Complete } \\
\text { soil }\end{array}$ & $\begin{array}{c}\text { Humic acids } \\
+ \text { humin }\end{array}$ & $\begin{array}{c}\text { Fulvic } \\
\text { acids }\end{array}$ & $\begin{array}{c}\text { Acetone } \\
\text { soluble }\end{array}$ & $\begin{array}{c}\text { Precip- } \\
\text { itated } \\
\text { gum }\end{array}$ \\
\hline $\begin{array}{c}\text { Per cent aggregation } \\
>0.5 \text { mm. diameter } \\
\begin{array}{c}\text { Per cent aggregation } \\
>0.1 \text { mm. diameter }\end{array}\end{array}$ & $0.946^{* *}$ & $0.917^{* *}$ & $0.954^{* *}$ & $0.752^{* *}$ & $0.671^{*}$ \\
\hline \hline
\end{tabular}

**Significant at 0.01 probability level

*Significant at 0.05 probability level 
conclusion is substantiated either from data obtained where the microbial gum content of the fulvic acid fraction was measured gravimetrically, or with the anthrone reagent. While it can be concluded that the 'gum' content of this fraction of the soil organic matter is associated with the aggregation phenomena, the level of aggregation is also dependent on other factors.

It is significant that appreciable contents of polysaccharides were found in the humin and humic acid as well as the fulvic acid fractions of the soil organic matter (1), and that, in the case of the poorly structured, highly leached Oxbow soil, the polysaccharide content of the humic acid - humin fraction correlated more highly with level of aggregation than that found in the precipitated gum fraction. It can be concluded that level of aggregation is a function, not only of the 'microbial gum' content of the soil (precipitated from the fulvic acid fraction), but also of the carbohydrate content of the humic acid and humin fraction. These latter fractions were formerly considered to contribute little towards aggregate stability.

\section{REFERENCES}

1. Acton, C. J., E. A. Paul, and D. A. Rennie. 1963. Measurement of the polysaccharide content of soils. Can. J. Soil Sci. 43:141-150.

2. Brink, R. H. Jr., P. Dubach, and D. L. Lynch. 1960. Measurement of carbohydrates in soil hydrolysates with anthrone. Soil Sci. 89:157-166.

3. Broadbent, F. E. 1953. The soil organic fraction. Advances in Agronomy 5: 153-183.

4. Chesters, G., O. J. Attoe, and O. N. Allen. 1957. Soil aggregation in relation to various soil constituents. Soil Sci. Soc. Amer. Proc. 21:272-277.

5. Forsyth, W. G. C. 1947. Studies on the more soluble complexes of soil organic matter. Biochem. J. 41:176-181.

6. Geoghegan, M. J., and R. C. Brian. 1948. Aggregate formation in soil. I. Influence of some bacterial polysaccharides on the binding of soil particles. Biochem. J. (London) 43:5-13.

7. Halstead, R. L. 1954. Soil aggregation as influenced by microbial gums, type of crop, lime, and fertilizers. Ph.D. thesis, University of Wisconsin, Madison, $W$ is.

8. Lueken, H., W. L. Hutcheon, and E. A. Paul. 1962. The influence of nitrogen on the decomposition of crop residues in the soil. Can. J. Soil Sci. 42:276-288.

9. Martin, J. P. 1946. Microorganisms and soil aggregation. II. Influence of bacterial polysaccharides on soil structure. Soil Sci. 61:157-166.

10. Mehta, N. C., H. Streuli, M. Müller, and H. Deuel. 1960. Role of polysaccharides in soil aggregation. J. Sci. Food Agr. 11:40-47.

11. Rennie, D. A., E. Truog, and O. N. Allen. 1954. Soil aggregation as influenced by microbial gums, level of fertility and kind of crop. Soil Sci. Soc. Amer. Proc. 18:399-403.

12. Toogood, J. A., and D. L. Lynch. 1959. Effect of cropping systems and fertilizers on mean weight-diameter of aggregates of Breton plot soils. Can. J. Soil Sci. 39:151-156. 